\title{
Middle Stage Heat Treatment for Microstructure Control of Reaction-Bonded Silicon Nitride-Silicon Carbide Composite
}

\author{
Naoki KONDO, Kenji KANEKO, ${ }^{*}$ Yoshikazu SUZUKI and Tatsuki OHJI \\ National Industrial Research Institute of Nagoya, 1-1, Hirate-cho, Kita-ku, Nagoya-shi, Aichi 462-8510 \\ *Ceramic Superplasticity Project, Japan Science and Technology Corporation, 2-4-1, Mutsuno, Atsuta-ku, Nagoya-shi, Aichi 456-8587 \\ 反応焼結窒化ケイ素-炭化ケイ素複合材料の中間熱処理による組織制御 \\ 近藤直樹·金子賢治 $*$ ·鈴木義和·大司達樹 \\ 名古屋工業技術研究所，462-8510 愛知県名古屋市北区平手町 1-1 \\ *科学技術振興事業団セラミックス超塑性プロシェクト，456-8587 愛知県名古屋市熱田区六野 2-4-1
}

\begin{abstract}
A silicon nitride-silicon carbide composite was fabricated from silicon and carbon powders by reactionbonding and post-hot-pressing procedures. The fabricated specimens had a nanocomposite-like microstructure with $\beta$-silicon nitride and $\beta$-silicon carbide. For some specimens, middle-stage heat treatment was applied before hot-pressing, which resulted in microstructure formation with large and elongated silicon nitride grains. With this microstructure, the specimens subjected to the middle stage heat treatment exhibited much higher fracture toughness than those not subjected to it.
\end{abstract}

[Received October 28, 1999; Accepted January 18, 2000]

Key-words : Silicon nitride-silicon carbide nanocomposite, Microstructure control, Middle stage heat treatment, Fracture toughness

1. Introduction

Silicon-nitride-based ceramics are one of the most important engineering ceramics, because of their high bending strength and high fracture toughness. However, the high cost of the raw silicon nitride powder makes silicon nitride an expensive material. In this study, we sequentially performed two well-known processing techniques, to overcome these problems.

The first step is a reaction-bonding $(\mathrm{RB})$ process, where low-cost silicon powder is used. However, this process has an inherent drawback in that it is difficult to control the nitridation reaction of silicon powder. ${ }^{1)}$ Recently, several researchers have reported that the nitridation reaction can be well controlled by adding $\mathrm{SiC}$ or carbon powder to produce silicon nitride-silicon carbide nanocomposites. ${ }^{2), 3)}$ In particular, Tsuda et al. produced reaction-bonded silicon nitride-silicon carbide nanocomposites, in which mixed powder of silicon and carbon was used as the starting powder. ${ }^{3)}$ The cost of carbon powder is also relatively low; thus the addition of carbon powder does not make a product expensive. Furthermore, the nanocomposites exhibit excellent mechanical properties compared to those of monolithic silicon nitrides. ${ }^{4)-6)}$ The second step is a hot-pressing (HP) process. One of the disadvantages of the RB process is the difficulty of obtaining a fully dense material. ${ }^{1)}$ To overcome this problem, post sintering procedures with sintering aids, which are added prior to or after $\mathrm{RB},{ }^{7)}$ have been conducted at higher temperatures under gas pressure ${ }^{2), 7)}$ or $\mathrm{HP}^{3)}$ conditions.

Following the above strategy, we developed a suitable heating processes combining $\mathrm{RB}$ and $\mathrm{HP}$ procedures in order to control the microstructure. It was found that application of middle-stage heat treatment (MHT) is effective to form a microstructure with large and elongated silicon nitride grains. This type of microstructure enhances toughening mechanisms including crack deflection, grain bridging and pull-out, realizing high fracture toughness. ${ }^{8), 9)}$

\section{Experimental}

Silicon powder (Kojundo Chemical Lab., Co., Ltd., 99.9 $\%, 1 \mu \mathrm{m})$, carbon black (Mitsubishi Chemical, \#750, 18 $\mathrm{nm}$ ), $\mathrm{Y}_{2} \mathrm{O}_{3}$ powder (Shin-Etsu Chemical Co., Ltd., UF) and $\mathrm{Al}_{2} \mathrm{O}_{3}$ powder (Sumitomo Chemical Co., Ltd., AKP 30) were first mixed. The weight ratio of $\mathrm{Si}: \mathrm{C}: \mathrm{Y}_{2} \mathrm{O}_{3}: \mathrm{Al}_{2} \mathrm{O}_{3}$ was $0.8084: 0.0782: 0.0709: 0.0425$. This mixture would ideally form 73.6 mass $\% \mathrm{Si}_{3} \mathrm{~N}_{4}-18.4$ mass $\% \mathrm{SiC}-5$ mass $\%$ $\mathrm{Y}_{2} \mathrm{O}_{3}-3$ mass $\% \mathrm{Al}_{2} \mathrm{O}_{3}$ (the weight ratio of $\mathrm{Si}_{3} \mathrm{~N}_{4}: \mathrm{SiC}$ was $0.8: 0.2)$, if reactions $\mathrm{Si}+\mathrm{C} \rightarrow \mathrm{SiC}$ and $3 \mathrm{Si}+2 \mathrm{~N}_{2} \rightarrow \mathrm{Si}_{3} \mathrm{~N}_{4}$ were completed. The mixed powder was ball-milled for $50 \mathrm{~h}$ in methanol using high-purity $\mathrm{Al}_{2} \mathrm{O}_{3}$ balls.

First, in order to evaluate the nitridation behavior, the powder compacts were heated at $1250^{\circ} \mathrm{C}$ for various periods of time in $0.1 \mathrm{MPa}$ nitrogen atmosphere. The mixed powder was cold isostatically pressed (CIP) under a pressure of 490 $\mathrm{MPa}$ to form columnar green bodies, $14 \mathrm{~mm}$ in diameter and $10 \mathrm{~mm}$ in height. The degree of nitridation was calculated from the weight change of the specimen.

Then, RB and post-HP procedures were studied for platelet-shaped specimens. The mixed powder of $25 \mathrm{~g}$ was compacted with a uniaxial pressure of $2.5 \mathrm{MPa}$ in a carbon die with a base of $45 \times 45 \mathrm{~mm}$. RB was conducted at $1250^{\circ} \mathrm{C}$ for $16 \mathrm{~h}$ in $0.1 \mathrm{MPa}$ nitrogen atmosphere, subsequently followed by the HP process at $30 \mathrm{MPa}$ and at $1850^{\circ} \mathrm{C}$ for $3 \mathrm{~h}$ in $0.1 \mathrm{MPa}$ nitrogen atmosphere. For some specimens, MHT at $1650^{\circ} \mathrm{C}$ for $3 \mathrm{~h}$ was applied before $\mathrm{HP}$ to control the microstructure. These procedures are schematically shown in Fig. 1. Hereafter, the specimens subjected to RB, RB and post-HP, and RB, MHT and post-HP are denoted as RB, RB-HP and RB-MHT-HP specimens, respectively.

$\mathrm{X}$-ray diffraction analysis was performed to examine the phases of the RB, RB-HP and RB-MHT-HP specimens. The $\alpha$-silicon nitride phase content was calculated by the calibration method. ${ }^{10)}$

Scanning electron microscopy (SEM) was conducted to examine the microstructures of the RB, RB-HP and RB-MHT-HP specimens. Specimens for SEM were cut, ground and polished, and then plasma-etched with $\mathrm{CF}_{4}$, followed by Au coating. The SEM images were analyzed using an image processing software, NIH Image (by W. Rasband, which is in the public domain).

Transmission electron microscopy (TEM) was conducted to examine the microstructure of the RB-MHT-HP 


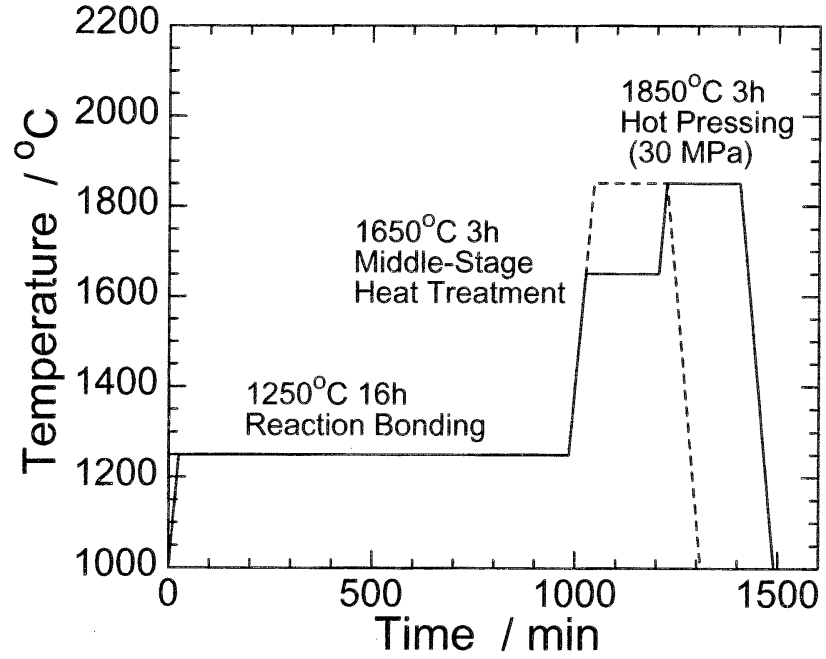

Fig. 1. Heating and pressing procedures for the RB-HP and RB-MHT-HP process. Full and dotted lines indicate the procedure with and without MHT, respectively.

specimen. Specimen for TEM was prepared by the standard mechanical thinning method. A disk with a diameter of 3 $\mathrm{mm}$ was cut from a bulk material, then mechanically thinned up to $50 \mu \mathrm{m}$. Dimpling was followed by Argon ion milling for 20 to $30 \mathrm{~h}$, starting with an acceleration voltage of $5 \mathrm{kV}$ and an ion beam current of $1 \mathrm{~mA}$ angled at $14^{\circ}$. Then the acceleration voltage was gradually reduced to 2.5 $\mathrm{kV}$, and the ion beam current to $0.5 \mathrm{~mA}$ angled at $12^{\circ}$, until a minute hole was formed at the center of the specimen disk. This process was necessary in order to avoid damaging the structure of grain boundaries and to obtain a broader optimum region for the electron microscopic observations. Since SiC does not show any charging-up effect under a high-energy electron beam, the specimen was not coated with a carbon layer. TEM imaging was carried out on a JEM $2010 \mathrm{~F}$ equipped with a $\mathrm{LaB}_{6}$ gun, having a point resolution of $0.18 \mathrm{~nm}$ operated at $200 \mathrm{kV}$.

For bending strength and fracture toughness measurements, specimens of $3 \times 4 \times 40 \mathrm{~mm}$ were cut from the RB-HP and RB-MHT-HP bodies; the stress face was kept perpendicular to the pressing direction. The three-point bending strength was measured with a span of $30 \mathrm{~mm}$ at a crosshead speed of $0.5 \mathrm{~mm} \cdot \mathrm{min}^{-1}$ at room temperature. The fracture toughness, $K_{\mathrm{IC}}$, was estimated by the singleedge- $\mathrm{V}$-notched beam (SEVNB) method using an equation introduced by Wakai et al. ${ }^{11)}$ The V-shaped notch with a depth of $2 \mathrm{~mm}$ was introduced using a tapered diamond wheatstone. Loading was carried out with a crosshead speed of $0.5 \mathrm{~mm} \cdot \mathrm{min}^{-1}$ at room temperature.

Propagated cracks in the RB-HT and RB-MHT-HP specimens were observed by SEM. The cracks were introduced by the Vickers indentation method on the polished and plasma-etched surface of each specimen. The applied load was $196 \mathrm{~N}$ and the loading period was $15 \mathrm{~s}$.

\section{Results}

$\mathrm{RB}$ study was conducted using the CIP columnar powder compact. Its initial density was $1.36 \times 10^{3} \mathrm{~kg} \cdot \mathrm{m}^{-3}$. The temperature of $1250^{\circ} \mathrm{C}$ for reaction bonding was selected for two reasons on the basis of previous papers: (1) a relatively higher $\alpha$-phase content in the reaction-bonded specimen was expected, and (2) reaction bonding was expected to be completed in a relatively short period.

The degree of nitridation for the $\mathrm{RB}$ process at $1250^{\circ} \mathrm{C}$ is shown in Fig. 2. Nitridation was about $85 \%$ after $16 \mathrm{~h}$ of

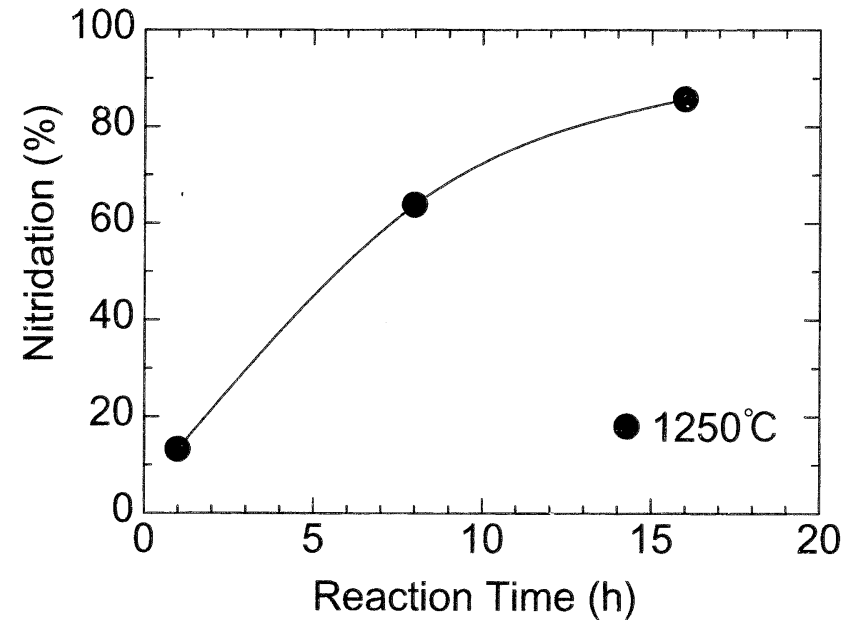

Fig. 2. Degree of nitridation at $1250^{\circ} \mathrm{C}$.

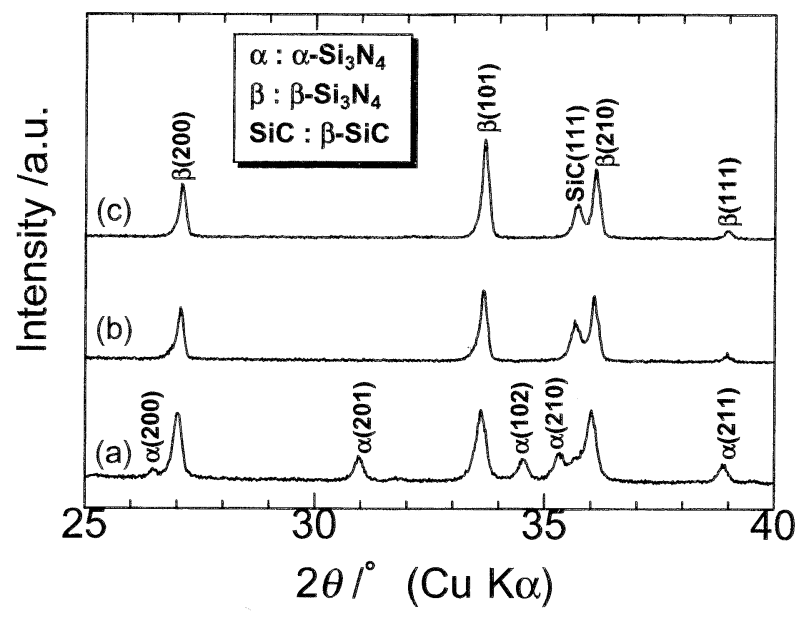

Fig. 3. Results of X-ray diffraction analyses of the (a) RB, (b) RB-HP and (c) RB-MHT-HP specimens.

soaking. The density of the RB specimen was $1.89 \times 10^{3} \mathrm{~kg}$. $\mathrm{m}^{-3}$. Note that the calculation was conducted under an assumption that the $\mathrm{SiC}$ formation was about $70 \%$ of the complete reaction as will be shown later. Time dependence of the formation was not considered; therefore, the degrees of nitridation after 1 and $8 \mathrm{~h}$ could be higher than the actual values. The result of X-ray diffraction (XRD) analysis is shown in Fig. 3(a), and the microstructure of the sample is shown in Fig. 4(a). As can be seen from Fig. 4(a), there are many pores in the RB specimen. Both $\alpha$ - and $\beta$-silicon nitride phases were formed after the RB process; from the analysis, the volume ratio was calculated as 42 : 58 . A $\beta$-silicon carbide peak was also found in the diffraction pattern. Neither silicon nor carbon peaks were detectable, though the weight change and analysis indicate that the reaction was not completed.

The RB-HP and RB-MHT-HP specimens were fabricated in a platelet shape. The optimum condition for RB was $1250^{\circ} \mathrm{C}$ for $16 \mathrm{~h}$, as determined from the result of the RB study (Fig. 2). The density of the specimen after MHT was $1.84 \times 10^{3} \mathrm{~kg} \cdot \mathrm{m}^{-3}$, and shrinkage was about $10 \%$ along the length of the basal plane. A density of $3.22 \times 10^{3} \mathrm{~kg} \cdot \mathrm{m}^{-3}$ was achieved after HP.

$\mathrm{X}$-ray diffraction analysis was also carried out on the RB-HP and RB-MHT-HP specimens. The results are shown in Fig. 3. In either specimen, the $\alpha$-silicon nitride 

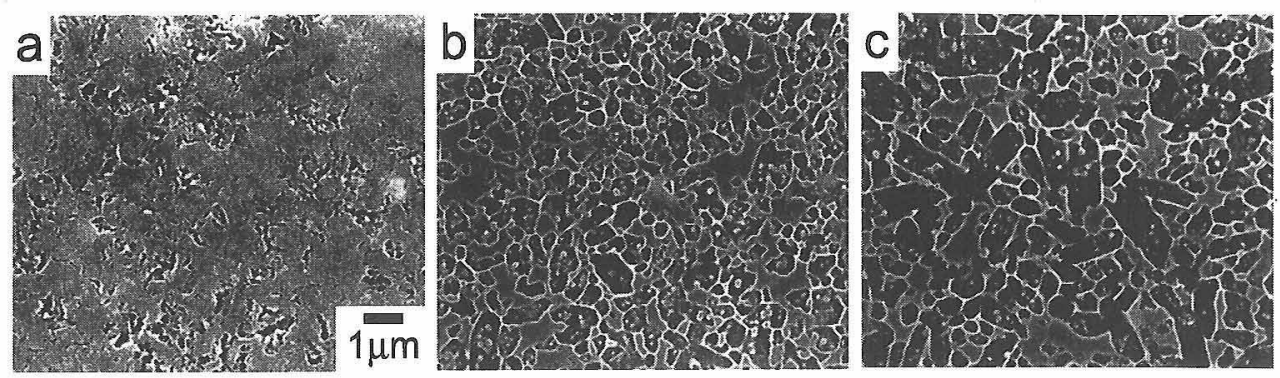

Fig. 4. SEM micrographs of the microstructure of the (a) RB, (b) RB-HP and (c) RB-MHT-HP specimens.

phase was not detected in the diffraction pattern. Therefore, these specimens consist only of $\beta$-silicon nitride and $\beta$-silicon carbide. The $\beta$-silicon carbide peaks of these specimens appeared more clearly than those of the RB specimen. Comparing the $\beta$-silicon carbide peaks of the RB and RB-HP specimens, about $70 \%$ of $\beta$-silicon carbide was formed after $\mathrm{RB}$; further formation of $\beta$-silicon carbide accompanied by the decomposition of silicon nitride due to residual carbon seems to occur during heating to $1750{ }^{\circ} \mathrm{C} .{ }^{6)}$ The RB-MHT-HP specimen exhibited a somewhat anisotropic microstructure, since (101) and (210) peaks of $\beta$-silicon nitride should have approximately the same heights (ASTM Card, 33-1160) in the case of isotropic silicon nitride.

Images of the microstructures of the RB-HP and RB-MHT-HP specimens obtained by SEM are shown in Figs. 4(b) and 4(c), respectively. Silicon nitride grains shown in the SEM micrographs were etched away by plasma etching, thus the silicon carbide grains and grain boundary glassy phase were enhanced. Neither cavities nor microcracks (approximately larger than $0.1 \mu \mathrm{m}$ ) were observed. In both micrographs, rod-shaped silicon nitride grains were observed; however, their grain sizes and aspect ratios were substantially different. The RB-MHT-HP specimen exhibits larger grain diameter and aspect ratio than the RB-HP one, as shown in Table 1. Note that the microstructural analysis was focused on larger grains, since mechanical properties, particularly fracture toughness, are strongly affected by large grains. ${ }^{8), 9)}$ Results of TEM indicate that silicon carbide particles, typically of $100-300 \mathrm{~nm}$ size, were located at the silicon nitride grain boundaries, and those of smaller size $(10-100 \mathrm{~nm})$ were dispersed inside the silicon nitride grains, as shown in Fig. 5. Further TEM investigation will be reported elsewhere. ${ }^{12)}$ Therefore, both the RB-HP and RB-MHT-HP specimens are concluded to have the nanocomposite-like microstructure. ${ }^{13)}$

The three-point bending strength and fracture toughness of the RB-HP and RB-MHT-HP specimens are summarized in Table 1. The RB-MHT-HP specimen exhibited a

Table 1. Grain Diameters, Aspect Ratios and Mechanical Properties of the Specimens

\begin{tabular}{lcc} 
& RB-HP & RB-MHT-HP \\
\hline $\begin{array}{l}\text { Grain Diameter }(\mu \mathrm{m}) \\
\text { (Average of All Grains) } \\
\text { (Average of Larger 10\% Grains) }\end{array}$ & 0.28 & 0.35 \\
\hline $\begin{array}{l}\text { Aspect Ratio } \\
\text { (Average of Larger 10\% Aspect Ratios) }\end{array}$ & 3.1 & 0.81 \\
\hline 3-Point Bending Strength (MPa) & $1240 \pm 92$ & $1179 \pm 70$ \\
\hline Fracture Toughness (MPa m ${ }^{1 / 2}$ ) & $5.6 \pm 0.41$ & $7.9 \pm 0.50$ \\
\hline
\end{tabular}

(The strength and toughness are indicated with standard deviations.)

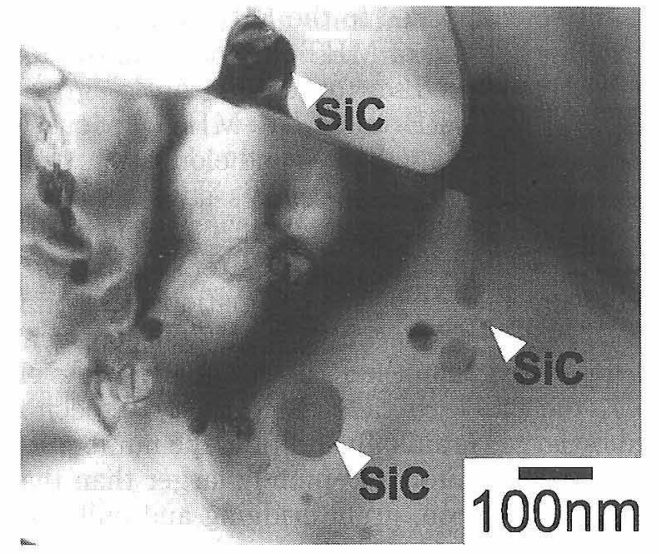

Fig. 5. TEM micrograph of the RB-MHT-HP specimen.

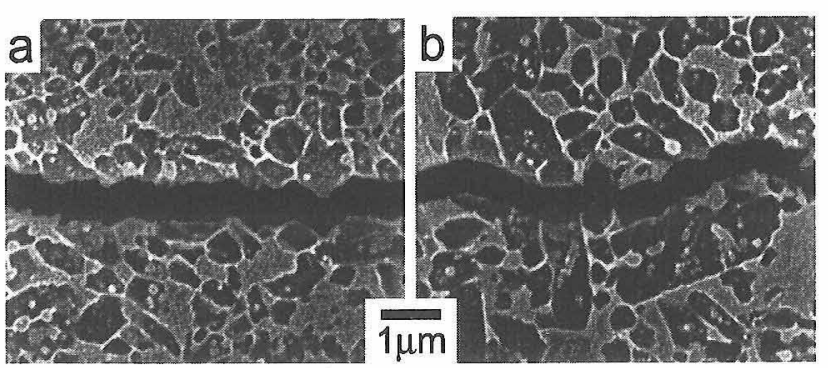

Fig. 6. Propagated cracks in the (a) RB-HP and (b) RB-MHTHP specimens.

much higher fracture toughness and a slightly lower bending strength than the RB-HP one. Propagated cracks in the RB-HP and RB-MHT-HP specimens are shown in Fig. 6. A crack in the RB-HP specimen runs in an almost straight line with a few grains being pulled out, while that in the RB-MHT-HP specimen propagates with deflection enhanced by larger grains. Note that the number of pulled-out grains in the RB-MHT-HP specimen is higher than that in the RB-HT specimen.

\section{Discussion}

The dominant silicon nitride phase in the $R B$ specimen was found to be the $\beta$-silicon nitride phase in this study. A larger amount of $\alpha$-silicon nitride phase is usually expected following the RB process at relatively lower temperatures, such as $1250^{\circ} \mathrm{C}^{1}{ }^{1)}$ Reaction-bonded silicon nitride with silicon carbide powder also contained higher amount of $\alpha$ phase. ${ }^{2)}$ Mitomo reported that $\beta$-silicon nitride is the dominant phase under an oxygen partial pressure of lower than $1 \times 10^{-13} \mathrm{MPa}{ }^{14)}$ The preferential $\beta$-silicon nitride phase formation observed in this study seems to be due to 
the low oxygen partial pressure caused by residual carbon, which exists after the RB process, leading to lower oxygen partial pressure due to its strong reduction effect.

The dominant $\beta$-silicon nitride phase formation after RB is disadvantageous for obtaining elongated $\beta$-silicon nitride grains after HP, since grain elongation is enhanced by phase transformation of silicon nitride from the $\alpha$ - to $\beta$-phase. ${ }^{15)}$ In addition, the presence of silicon carbide strongly inhibits grain growth and elongation.4),5) With these disadvantages, high fracture toughness cannot be realized in the RB-HP specimen.

As known from Table 1, MHT is useful to overcome the above two disadvantages. The RB-MHT-HP specimen had larger and more elongated grains, and exhibited higher fracture toughness, compared to the RB-HP one.

With the application of MHT, the pores in the RB specimen should play a key role for grain growth and elongation. ${ }^{16)}$ The $\mathrm{RB}$ and RB-MHT specimens had sufficient space for grain growth and elongation: the density was about $60 \%$ after MHT. In this study, $1650^{\circ} \mathrm{C}$ seems suitable for MHT, since the degree of densification and grain growth were moderate at this temperature such that the subsequent microstructural formation was optimized.

The RB-MHT-HP specimen exhibited a much higher fracture toughness than the RB-HP specimen. As shown in Fig. 6(b), the crack in the RB-MHT-HP specimen was deflected by larger grains. In addition, the number of pulledout grains in the former is definitely larger than that in the latter. Crack deflection, grain bridging and pull-out are enhanced by the large and elongated grains. ${ }^{8), 9)}$ Therefore, the RB-MHT-HP process for obtaining specimens with large and elongated grains is ideal for achieving higher fracture toughness.

\section{Conclusion}

A silicon nitride-silicon carbide composite was fabricated from silicon and carbon powders by combining reactionbonding and post-hot-pressing procedures. The dominant silicon nitride phase was $\beta$-phase and the grains were small with lower aspect ratio, resulting in relatively low fracture toughness. For some specimens, however, middle-stage heat treatment was applied before hot pressing, which enhanced microstructure formation with large and elongated $\beta$-silicon nitride grains. With this microstructure, the fracture toughness was substantially improved compared to that of the specimen not subjected to the middle-stage heat treatment.

\section{References}

1) A. J. Moulson, J. Mater. Sci., 14, 1017-51 (1979).

2) S.-Y. Lee, J. Am. Ceram. Soc., 81, 1262-68 (1998).

3) H. Tsuda, T. Otsuka, H. Mabuchi and K. Morii, Key Eng Mater, 161-163, 63-66 (1999).

4) T. Hirano, T. Ohji and K. Niihara, Mater. Lett., 27, 53-58 (1996).

5) J.-F. Yang, Y.-H. Choa, J. P. Singh and K. Niihara, J. Ceram. Soc. Japan, 106, 951-57 (1998).

6) Y. Kinemuchi, T. Yanai and K. Ishizaki, Nano Stract. Matel., 9, 23-32 (1997).

7) J. A. Mangels and G. J. Tennenhouse, Am. Ceram. Soc. Bull., 59, 1216-22 (1980).

8) P. Sajgalik, J. Dusza and M. J. Hoffmann, J. Am. Ceram. Soc., 78, 2619-24 (1995).

9) H. J. Kleebe, G. Pezzotti and G. Ziegler, J. Am. Ceram. Soc., 82, 1857-67 (1999).

10) K. Suzuki and Y. Kanno, J. Ceram. Soc. Japan (Yogyo-KyokaiShi ), 92, 101-02 (1984) [in Japanese].

11) F. Wakai, S. Sakaguchi and Y. Matsuno, J. Ceram. Soc. Japan (Yogyo-Kyokai-Shi), 93, 479-80 (1985) [in Japanese].

12) K. Kaneko and N. Kondo, submitted to Scripta Meter.

13) K. Nihhara, J. Ceram. Soc. Japan (Seramikkusu Ronbunshi), 99, 974-82 (1991).

14) M. Mitomo, J. Am. Ceram. Soc., 58, 527 (1975).

15) M. Mitomo, J. Ceram. Soc. Japan (Seramikkusu Ronbunshi), 99, 1014-25 (1991).

16) C. Kawai and A. Yamakawa, J. Am. Ceram. Soc., 80, 2705-08 (1997) 